\title{
Economic Growth, Independent Innovation and Industrial Structure: Evidence from Beijing, Tianjin and Hebei
}

\author{
Zhenxin $\mathrm{Wu}^{1}$ and Zhixian $\mathrm{Du}^{2, *}$ \\ ${ }^{1,2}$ School of Economics and Management, North China University of Technology, Beijing 100144, China \\ ${ }^{*}$ Corresponding author
}

\begin{abstract}
We use semi-parametric panel space vector autoregression approach and impulse response function to analyze the dynamical interplay among economic growth, independent innovation and industrial structure in Beijing, Tianjin and Hebei. Estimation results show that, independent innovation and industrial structure shocks of Beijing gave a weak positive effect on economic growth, independent innovation and industrial structure of the contiguity areas. Industrial structure shocks of Tianjin and Hebei gave a reverse ' $N$ ' shaped effect on economic growth, independent innovation and industrial structure of the contiguity areas. Besides, we use the semi-parametric part to analyze the influence of tax structure on the three, it is found that the ratio of commodity tax to income tax is reasonable between 5.7 and 5.8, which can promote the coordinated development between economic growth, independent innovation and industrial structure.
\end{abstract}

Keywords - semi-parametric panel space vector auto-regression model; economic growth; independent innovation; industrial structure; tax structure

\section{INTRODUCTION}

With the continuous development of science and technology, for developing countries, the key to economic growth is the integration of technology and industry. The proposal of the "Beijing-Tianjin-Hebei collaborative development" has accelerated the process of regional cooperation in the three regions, so more researchers focus on the relationship between economic development, innovation capability and industrial structure in the three regions.

The relationship among economic growth, independent innovation and industrial structure has been widely analyzed in the literature, both theoretically as well as empirically. In theoretical research, studies on the impact of independent innovation on economic growth have been predominantly based on the endogenous economic growth theory, where growth is driven by technological progress. The size and growth rate of various industrial sectors determine the overall size and growth rate of the national economy [1, 2]. The effect of technological progress on industrial structure is divided into two aspects: one is high-level industrial structure, which technological innovation brings about the birth and growth of emerging industries, the other is the rationalization of industrial structure, which the promotion of new technologies in traditional industries increases the productivity and makes the resources reasonably distributed [3]. Reference [4, 5] has examined the impact of commodity tax and income tax on economic growth, industrial structure and independent innovation. In this paper, we use Figure 1 as the theoretical base for analysis.
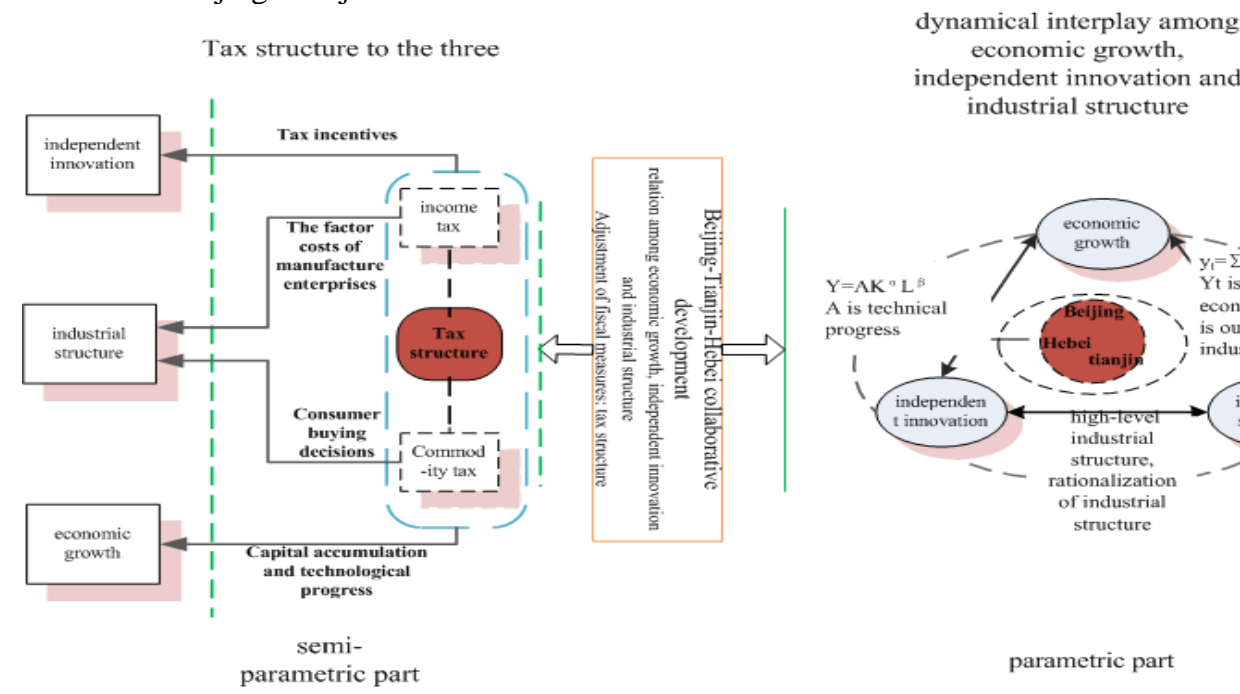

FIGURE I. THE THEORETICAL RELATIONSHIP OF THE FOUR VARIABLES 
In empirical research, R\&D investment promotes economic growth by increasing productivity [6]. The relationship between R\&D investment and economic growth is that there is a long-term and stable relationship between them, and the economic development is promoted to some extent $[7,8]$. The relationship between R\&D investment and industrial structure is that R\&D investment has positively promoted the adjustment of industrial structure [9]. With the development of space econometrics, some empirical work has evolved from this focus on economic growth, independent innovation and industrial structure. These studies have established that there is spatial spillover effect on R\&D investment and industrial structure $[10,11]$.

In summary, researchers use the single-equation or traditional model to study the relationship. It is a major national strategic task in the coming years that we must strengthen "Beijing-Tianjin-Hebei collaborative development" and accelerate the construction of the Xiong'an district. Therefore, further study of the dynamic relationship among economic growth, independent innovation and the industrial structure of Beijing-Tianjin-Hebei has important practical significance. But the single-equation model or single-equation model with spatial factor or traditional VAR model can't reflect this relationship and the shocks of endogenous variables in temporal and spatial impact, spatial VAR model overcome the weaknesses of both. Moreover, when studying economic development issues, the role of the government can't be ignored. The government regulates economic development through fiscal and monetary means. The tax structure affects the adjustment of industrial structure and economic growth from different perspectives, and the influence is not a simple linear effect [5], so the tax structure is introduced into the model in the form of nonparametric. In view of the above reasons, the semi-parametric spatial panel vector autoregressive model is used to study the relationship among the four variables.

\section{VARIABLES AND DATA}

GDP and per capita GDP are the key indicators for measuring the level of economic development in a country or region, so we measured economic growth using real per capita GDP of each province, and the real GDP is expressed in 1978 prices. The scale of $R \& D$ are usually used to reflect the scientific and technological strength and core competitiveness of a country, so we measured independent innovation using R\&D investment intensity (the proportion of R\&D investment in GDP). In order to overcome the one-sidedness of the industrial structure measured by a single indicator, we used hierarchical index method to measure industrial structure [4], which changes in the three industries accounts for $25 \%$, and labor distribution structure accounts for $30 \%$, and industry sector contribution rate accounts for $45 \%$. The current tax structure basically divided into three categories, a single income tax system, a single commodity tax and a mix of income tax and commodity tax. The commodity tax is the main tax system at this stage in China [12]. The tax structure is reflected in the ratio of commodity tax to income tax. Income tax includes corporate income tax and personal income tax. It is difficult to collect the commodity tax data, so the commodity tax is replaced by the sum of value added tax, sales tax and consumption tax [5].

This study uses data from China statistical yearbook, China taxation yearbook, as well as statistical yearbook and taxation yearbook of each province. The sample period is from 2000 to 2015, and the data are taken the natural logarithm to linearize its trend and eliminate heteroscedasticity.

\section{MODEL SETtingS}

Semi-parametric panel space VAR model combines panel model, spatial model and VAR model, and takes the advantage of parametric and non-parametric models. It not only avoids the wrong setting of some endogenous variables in parameter model, but also avoids the large amount of data in nonparametric model, at the same time, it can analyze the temporal and spatial influence of each endogenous variable, so it has practical significance to analyze regional economic issues.

$$
\begin{gathered}
{\left[\begin{array}{c}
p G D P_{i t} \\
R D_{i t} \\
I S_{i t}
\end{array}\right]=\left[\begin{array}{lll}
\alpha_{11} & \alpha_{12} & \alpha_{13} \\
\alpha_{21} & \alpha_{22} & \alpha_{23} \\
\alpha_{31} & \alpha_{32} & \alpha_{33}
\end{array}\right]\left[\begin{array}{c}
p G D P_{i t-1} \\
R D_{i t-1} \\
I S_{i t-1}
\end{array}\right]+\left[\begin{array}{lll}
\beta_{11} & \beta_{12} & \beta_{13} \\
\beta_{21} & \beta_{22} & \beta_{23} \\
\beta_{31} & \beta_{32} & \beta_{33}
\end{array}\right]} \\
{\left[\begin{array}{c}
p G D P_{i t-1}^{*} \\
R D_{i t-1}^{*} \\
I S_{i t-1}^{*}
\end{array}\right]+\left[\begin{array}{c}
M_{1}\left(T S_{i t}\right) \\
M_{2}\left(T S_{i t}\right) \\
M_{3}\left(T S_{i t}\right)
\end{array}\right]+\left[\begin{array}{l}
\mu_{1 i t} \\
\mu_{2 i t} \\
\mu_{3 i t}
\end{array}\right] \quad i=1,2,3 ; t=1, \ldots, 16}
\end{gathered}
$$

Let $p G D P_{i t-1}, R D_{i t-1}, I S_{i t-1}$ be the lagged period of the endogenous variable; $p G D P_{i t-1}^{*}, R D_{i t-1}^{*}, I S_{i t-1}^{*}$ the spatial lagged period of the endogenous variable; $M_{1}\left(T S_{i t}\right), M_{2}\left(T S_{i t}\right), M_{3}\left(T S_{i t}\right)$ the tax structure of non-parametric items; The construction of spatial weight matrix in this paper takes the form of economic weighting. We can express the weight matrix as:

$$
\left\{\begin{array}{l}
\mathrm{WE}=\mathrm{W} * \operatorname{diag} \frac{\bar{y}_{1}}{\bar{y}}, \frac{\bar{y}_{2}}{\bar{y}}, \cdots, \frac{\bar{y}_{n}}{\bar{y}} \\
\bar{y}_{i}=\left(t_{1}-t_{0}+1\right)^{-1} \sum_{t=t_{0}}^{t_{1}} y_{i t} \\
\bar{y}=n\left(t_{1}-t_{0}+1\right)^{-1} \sum_{i=1}^{n} \sum_{t=t_{0}}^{t_{1}} y_{i t}
\end{array}\right.
$$

Let $\mathrm{W}$ be a spatial contiguity matrix, with a zero diagonal, and the off-diagonal 1 indicating contiguity of locations $i$ and $j$, and 0 indicating non-contiguity of locations $i$ and $j$.

\section{EMPIRICAL ANALYSIS}

\section{A. Non-linear Interdependence Test}

In order to verify the non-linear interdependences between the tax structure and the other three variables, the curve of economic growth, independent innovation, industrial structure and tax structure were fitted respectively, the results are presented in figure 2. 

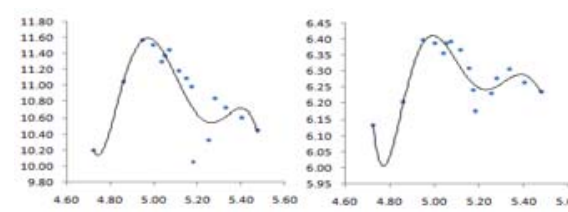

pGDP and TS RD and TS

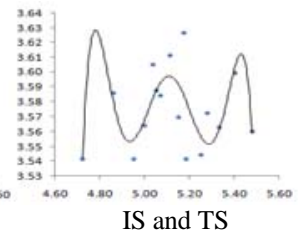

FIGURE II. NONLINEAR RELATIONSHIP BETWEEN TAX STRUCTURE AND THREE VARIABLES

Figure2 shows that the relationship between these three variables and tax structure is not a simple linear interdependence, so it is consistent with the model's set that the tax structure is introduced in the form of non-parametric.

\section{B. Spatial Correlation Test}

The Moran's I and Geary's C are indicators of the global spatial correlation of regional economic activities, which are defined as:

$$
\begin{aligned}
& I=n \sum_{i=1}^{n} \sum_{j=1}^{n} W_{i j}\left(X_{i}-\bar{X}\right)\left(X_{j}-\bar{X}\right)\left(\sum_{i=1}^{n} \sum_{j=1}^{n} W_{i j} \sum_{i=1}^{n}\left(X_{i}-\bar{X}\right)^{2}\right)^{-1} \\
& =\sum_{i=1}^{n} \sum_{j=1}^{n} W_{i j}\left(X_{i}-\bar{X}\right)\left(X_{j}-\bar{X}\right)\left(S^{2} \sum_{i=1}^{n} \sum_{j=1}^{n} W_{i j}\right)^{-1}
\end{aligned}
$$

Let $S^{2}=n^{-1} \sum_{i=1}^{n}\left(X_{i}-\bar{X}\right)^{2} ; \bar{X}=n^{-1} \sum_{i=1}^{n} X_{i}$; Where $X_{i}$ is the observation value in region $i, W_{i j}$ is spatial weight matrix.

$$
\begin{aligned}
& C=(n-1) \sum_{i=1}^{n} \sum_{j=1}^{n} w_{i j}\left(x_{i}-x_{j}\right)^{2} \\
& *\left(2 \sum_{i=1}^{n} \sum_{j=1}^{n} w_{i j} \sum_{i=1}^{n}\left(x_{i}-\bar{x}\right)^{2}\right)^{-1} \approx 1-I
\end{aligned}
$$

\begin{tabular}{|c|c|c|c|c|}
\hline \multirow{2}{*}{ variable } & \multicolumn{2}{|c|}{$2000-2003$} & \multicolumn{2}{|c|}{ 2004-2007 } \\
\hline & $I$ & $C$ & $I$ & $C$ \\
\hline pGDP & $-0.616 * * *$ & $1.549 * * *$ & $-0.598 * * *$ & $1.531^{* * *}$ \\
\hline $\mathrm{RD}$ & $-0.574 * * *$ & $1.5^{* * *}$ & $-0.646^{* * *}$ & $1.577 * * *$ \\
\hline IS & $-0.636 * * *$ & $1.568^{* * *}$ & $-0.567 * * *$ & $1.488^{* * *}$ \\
\hline \multirow{2}{*}{ variable } & \multicolumn{2}{|c|}{ 2008-2011 } & \multicolumn{2}{|c|}{$2012-2015$} \\
\hline & $I$ & $C$ & $I$ & $C$ \\
\hline pGDP & $-0.587 * * *$ & $1.514^{* * *}$ & $-0.617 * * *$ & $1.54^{* * *}$ \\
\hline $\mathrm{RD}$ & $-0.653 * * *$ & $1.587 * * *$ & $-0.653^{* * *}$ & $1.588^{* * *}$ \\
\hline IS & $-0.591 * * *$ & $1.524 * * *$ & $-0.644 * * *$ & $1.578 * * *$ \\
\hline
\end{tabular}

TABLE I. SPATIAL CORRELATION TEST OF BEIJING, TIANJIN AND HEBEI

a. $* * *, * *$, and $*$ indicate significance at the $0.01,0.05$, and 0.1 levels, respectively

From table1, we reject the null of no spatial correlation among per capita GDP, independent innovation and industrial structure at the $1 \%$ levels of significance, implying that there is spatial correlation among the three.

\section{Unit Root Test and Granger Causality Test}

In order to better study the relationship among economic growth, independent innovation, industrial structure and tax structure and avoid false regression, we tested the stationarity of the sequence by IPS method, which suggests the three sequences are stable.

For panel Granger causality test, there is no standard model, Eviews8 provides two kinds of test. One is to take the panel data as a whole, the coefficient is the same between crosssections. The other is proposed by Dumitrescu-Hurlin, allowing coefficients differ between cross-sections. This paper combines these two methods to test the causal relationship between variables. The results show that, first, there is a two-way causal relationship between economic growth and independent innovation. Second, evidence shows two-way Granger causality for independent innovation and industrial structure. Third, we find evidence of one-way Granger causality running from industrial structure to economic growth, and a positive effect exist. Forth, evidence shows one-way Granger causality running from tax structure to economic growth, industrial structure and independent innovation. So it is consistent with the model's set that the tax structure is introduced in the form of exogenous variables.

\section{Model Solution and Result Analysis}

According to the curse dimension of estimation of nonparametric component and AIC rules, we choose the lag length of 1 , and build the model following equation (1). The GMM method is used for estimation to solve the endogenous explanatory variables problem. We use R and MATLAB tools

\begin{tabular}{|c|c|c|c|}
\hline & $p G D P$ & $R D$ & $I S$ \\
\hline \multirow{2}{*}{ pGDP(-1) } & -0.1308 & 0.1781 & -0.8809 \\
\hline & 1.2605 & 1.6081 & 2.6235 \\
\hline \multirow{2}{*}{$\mathrm{RD}(-1)$} & 0.0063 & -0.0836 & -0.3955 \\
\hline & 0.5520 & 0.7042 & 1.1489 \\
\hline \multirow{2}{*}{ IS(-1) } & -0.1703 & -0.0703 & -0.2497 \\
\hline & 0.2943 & 0.3754 & 0.6125 \\
\hline \multirow{2}{*}{$\operatorname{pGDP}^{*}(-1)$} & -0.0015 & 0.1839 & 0.4475 \\
\hline & 0.5482 & 0.7838 & 1.4672 \\
\hline \multirow{2}{*}{$\mathrm{RD}^{*}(-1)$} & 0.0008 & 0.0521 & 0.1844 \\
\hline & 0.2401 & 0.3432 & 0.6425 \\
\hline \multirow{2}{*}{ IS*(-1) } & 0.0542 & 0.1601 & 0.2275 \\
\hline & 0.1280 & 0.1830 & 0.3425 \\
\hline $\mathrm{M}_{1}$ (TS) & \multirow{3}{*}{$\begin{array}{l}\text { First line in } \\
\text { Figure } 4\end{array}$} & \multirow{3}{*}{$\begin{array}{l}\text { Second line in } \\
\text { Figure } 4\end{array}$} & \multirow{3}{*}{$\begin{array}{c}\text { Third line in } \\
\text { Figure } 4\end{array}$} \\
\hline $\mathrm{M}_{2}$ (TS) & & & \\
\hline $\mathrm{M}_{3}(\mathrm{TS})$ & & & \\
\hline
\end{tabular}
for parameter estimation. The estimation results are shown in Table 2.

TABLE II. PARAMETER ESTIMATION RESULTS

a.The previous line is the parameter value, the next line is the corresponding $t$ value

The results show that not all coefficients for spatial and temporal lagged variables are significant, but also illustrate the necessity of adding spatial items. As the classical VAR model, 
interpreting the results of model parameter is not significant and requires further analysis with impulse response.

The impulse response function describes the effect on the immediate and future values of endogenous variables after a shock of one standard deviation. The impulse source of spatial and temporal can select endogenous variables of different cross-sections. In 'Beijing-Tianjin-Hebei collaborative development' plan, Beijing as the political, economic, cultural and technological center of China take the upgrading the ability of independent innovation as its main objective. Tianjin and Hebei mainly undertake the industrial transfer of Beijing. Therefore, we choose the independent innovation of Beijing as the source of shock and the industrial structure of Beijing, Tianjin and Hebei as the impact source for the spatial and temporal impulse response analysis. Figure 3 shows the 'response-impulse' process.

The first line of Figure 3 shows the response of economic growth, independent innovation and industrial structure of Beijing, Tianjing and Hebei to shocks in the independent innovation of Beijing. The economic growth of the three regions showed a positive response, reaching the maximum in the second phase, but a weaker response in Tianjin and Hebei, indicating that independent innovation in Beijing has't played a role in driving economic growth around the region. Independent innovation response in Beijing is the largest but the effect dies out relatively quickly in the second phase, but independent innovation response in Tianjin and Hebei is more weaker. This shows that, in Beijing, independent innovation has no effect on the proliferation of neighboring provinces. The industrial structure in Beijing showed a negative response, reaching the maximum in the second phase, indicating that independent innovation can't promote the industrial structure in the short run. The industrial structure in Hebei and Tianjin showed positive effects, reaching maximum in the second phase.

The second line of figure 3 shows the response to the industrial structure of Beijing. Economic growth and independent innovation of Beijing showed an alternating change from a negative response to a positive response with a more obvious negative effect, indicating that the industrial structure in Beijing is not yet rational enough, and can't contribute to economic growth and independent innovation. The industrial structure in Beijing showed the positive effect first and negative effect next. The economic growth, independent innovation and industrial structure of Hebei and Tianjin showed an alternating change from the positive to the negative, reaching maximum in the second phase, but the response was much smaller than that of Beijing, indicating that the spatial diffusion effect of industrial structure was small.

The last two line of figure 3 shows the response to industrial structure of Tianjin and Hebei. Economic growth and independent innovation of its own region showed " $\mathrm{N}$ " wave convergence, the positive effect was greater than the negative effect, and the industrial structure showed the negative effect first and positive effect next. Economic growth, independent innovation and industrial structure of the contiguity provinces showed an inverted "N" shaped wave convergence, with the second phase reaching negative maximum.
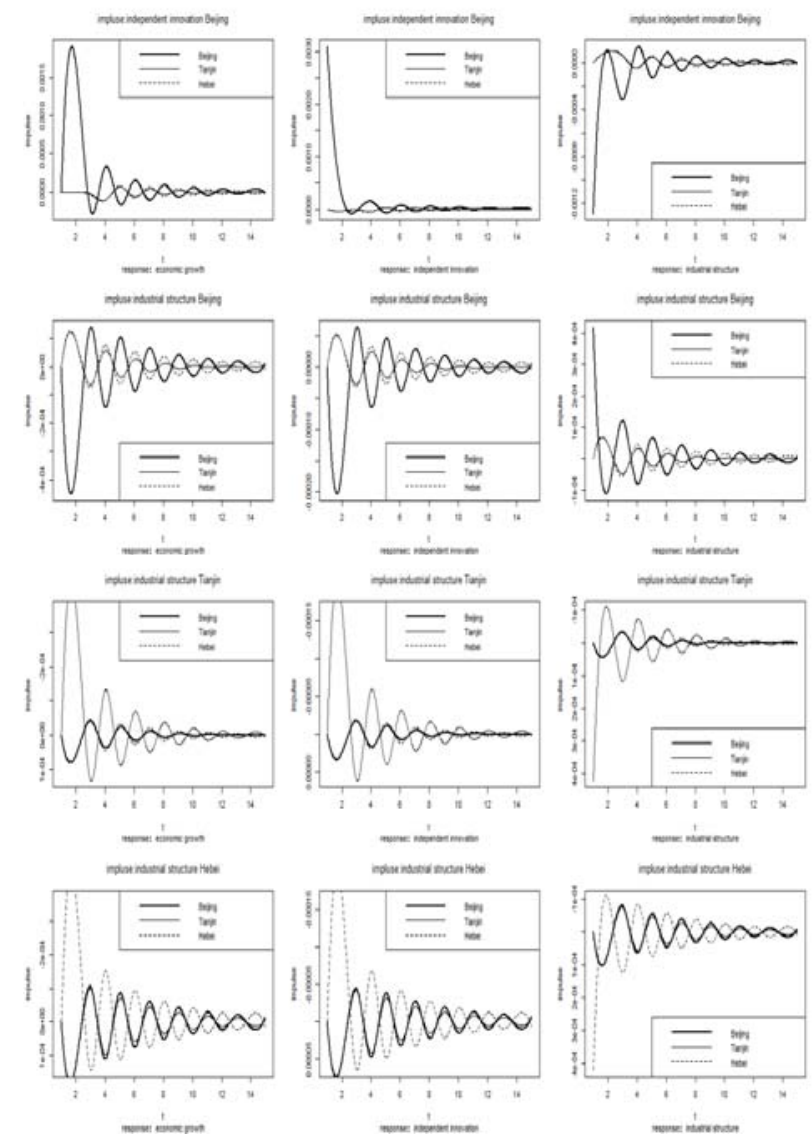

FIGURE III. IMPULSE FIGURE

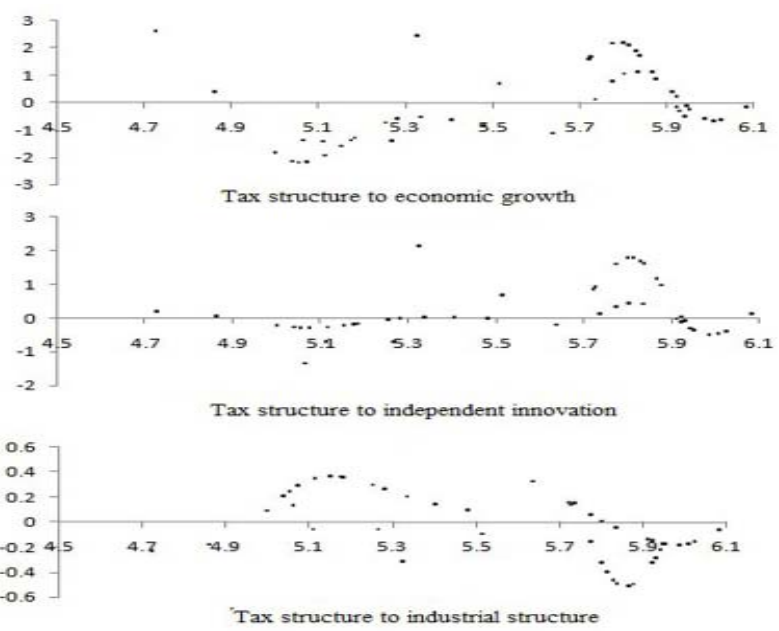

FIGURE IV. DERIVATIVE GRAPHS OF TAX STRUCTURE

According to the three derivative graphs, the higher commodity tax has a positive effect on economic growth and independent innovation. The ratio of commodity tax to income tax is 5.7 to 5.9 , which has a positive effect on economic growth and independent innovation, but lower 5.7 or higher than 5.9 have inhibitory effect. The tax structure is 5 to 5.3 and 5.6 to 5.8 to promote the industrial structure, therefore, in order to achieve the coordinated development with economic growth, 
independent innovation and industrial structure, the ratio of commodity tax to income tax is more reasonable between 5.7 and 5.8 .

\section{CONCLUSION}

Based on the data of Beijing, Tianjin, Hebei from 2000 to 2015, we use the semi-parametric panel space vector autoregression model and impulse response function to analyze the relation among economic growth, independent innovation and industrial structure, and also analyze the non-linear interdependence between the tax structure and the three endogenous variables by derivative graphs. The main conclusions are as follows:

Economic growth and independent innovation of Beijing have a positive response to the shock in innovation of Beijing, which proves that independent innovation as an endogenous variable to promote economic growth. But the industrial structure has a negative response. From the R\&D investment in Beijing in 2009, most are in basic and applied research, investment in $\mathrm{R} \& \mathrm{D}$ is not enough. The basic research funding is 2.1 billion, accounting for $30 \%$, the applied research funding is 4.32 billion, accounting for $61.7 \%$, the experimental development funding is 580 million, accounting for $8.3 \%$. Furthermore, over the years, governments have simply emphasized economic growth. The stimulus policies introduced have even shown short-term effects. The major inputs are still leaning to those fast-moving traditional industries such as iron and steel and cement industries. As a result, unbalanced distribution of innovation resources among industries restricted industrial structure adjustment. The impulse of Beijing's independent innovation and industrial structure gave a weak positive effect on economic growth, independent innovation and industrial structure of the surrounding areas, we believe that this is a direct consequence of historical and institutional causes, various resources have been excessively concentrated in central city such as Beijing, and the siphon effect is stronger than diffusion effect on the surrounding areas.

The impact of industrial structure of Hebei and Tianjin on the economic growth and independent innovation in their own region showed an alternating change from a positive response to a negative response, which the positive response dominates. Industrial structure showed negative first and positive effect next. However, the economic growth, independent innovation and the industrial structure of the contiguity areas showed an inverted "N" shape. In the past 30 years, Hebei and Tianjin have promoted the economic growth through the optimization of the employment structure and the strong development of the tertiary industry. The economic growth is the material basis of independent innovation and promotes the its development. However, on the whole, the industrial structure is not reasonable enough and the proportion of primary industry is relatively large. In the industrial structure, the proportion of traditional industries is relatively large, but the emerging industries have just started. Under the background of 'BeijingTianjin-Hebei collaborative development', with the adjustment of the industrial structure in Hebei and Tianjin, it is expected that the manpower and resources of Beijing will migrate to Tianjin and Hebei, so there is a negative effect on economic growth and independent innovation of Beijing in the short term.
From the derivative of the tax structure, the ratio of commodity tax and income tax between 5.7 to 5.8 is more reasonable. As an important means of government regulation of economy, tax revenue affects economic growth by affecting the accumulation of capital and technological progress. Higher income taxes promote the industrial restructuring while the commodity tax is inversely proportional to industrial restructuring [4]. Therefore, it is necessary to harmonize the taxes on commodities and income tax to promote the optimization and upgrading of the industrial structure.

\section{ACKNOWLEDGEMENTS}

This paper is supported by Beijing Social Science Foundation (Grant No.16LJC008) and Foundation for The Excellent Youth Scholars of Beijing (Grant No.2016000020124G021) and university students science and technology activities of NCUT.

\section{REFERENCES}

[1] Y. F. Lin, Development Strategy, Viability and Economic Convergence China Economic Quarterly. pp. 269-300, 2002

[2] D.Acemoglu, F. Zilbotti, Productivity differences Quarterly Journal of Economics. pp.563-606,2001

[3] H.W. Guo, Correlation Analysis of Regional Independent Innovation and Industrial Structure Optimization---evidence from dongbei. Economic Research Guide . pp.112-113, 2010

[4] D.Y. Chu and K.C.Jian, Fiscal Policy and Adjustment of Industrial Structure - An Empirical Analysis Based on the Dual Perspectives of Aggregate Quantity and Structural Effect .Economist. pp. 80-91, 2014

[5] D.Y. Chu and F. Ji, Tax System Structural Change and Industrial Structure Adjustment: Theoretical Interpretation and Empirical Evidence in China. Economist . pp.70-78, 2017.

[6] A. Estrada and J. Montero, R\&D Investment and Endogenous growth: A SVAR Approach . Working Paper Series Documents de Trabajo ,2009

[7] N.I.John, The Contribution of R\&D Expenditure to Economic Growth in Developing Economies, Social Indicators Research. Vol.124, pp.727745, December 2015.

[8] O. O. Cetenak and G. Oransay, Economic Growth and Dynamic R\&D Investment Behavior, Global Business Strategies in Crisis. pp. 243-259, 2017.

[9] T. Altenburg, H. Schmitz and A.Stamm, Breakthrough? China's and India's Transition from Production to Innovation, World Development. Vol. 36, pp.325-344, 2008

[10] X.F. Chen, Z.Y.Liu and C.L.Ma, Chinese innovation-driving factors: regional structure, innovation effect, and economic developmentempirical research based on panel data, The Annals of Regional Science. Vol. 59, pp. 43-68, July 2017.

[11] K.Dimitris and P. George, Industrial growth, economic integration and structural change: evidence from the EU new member-states regions, The Annals of Regional Science. Vol. 45, pp. 667-680, December 2010.

[12] G.Q. Ma, The level of economic development, the goal of tax policy and the mode of tax structure, Taxation research . pp.3-16, May 2016. 